\title{
Telepharmacy: A Potential Alternative Approach for Diabetic Patients During the COVID-19 Pandemic
}

\author{
Ghina Nadhifah Iftinan (D) \\ Nasrul Wathoni (iD ${ }^{2,3}$ \\ Keri Lestari iD ${ }^{3,4}$ \\ 'Bachelor Program in Pharmacy, Faculty \\ of Pharmacy, Universitas Padjadjaran, \\ Sumedang, 45363, Indonesia; \\ ${ }^{2}$ Department of Pharmaceutics and \\ Pharmaceutical Technology, Faculty of \\ Pharmacy, Universitas Padjadjaran, \\ Sumedang, 45363, Indonesia; ${ }^{3}$ Indonesia \\ Test Trace and Isolation (InaTTI), \\ Medication Therapy Adherance Clinic \\ (MTAC), Universitas Padjadjaran, \\ Sumedang, 45363, Indonesia; \\ ${ }^{4}$ Department of Pharmacology and \\ Clinical Pharmacy, Faculty of Pharmacy, \\ Universitas Padjadjaran, Sumedang, \\ 45363, Indonesia
}

\begin{abstract}
The use of telepharmacy technology allows pharmacists to provide clinical pharmaceutical services to patients with diabetes mellitus (DM) who need regular services during the COVID-19 pandemic while maintaining distance and minimizing face-to-face meetings. The purpose of this review article was to identify the impact of telepharmacy intervention by pharmacists in diabetic patients by reviewing clinical outcomes and patient therapy adherences. A literature search was conducted through the PubMed database using the terms "telemedicine", "telepharmacy", "telehealth" and "telephone" in combination with "pharmacist", 'diabetes' and 'COVID-19' or "Pandemic". From a total of 67 articles identified, 14 research articles conform to the inclusion criteria. Telephone is the most widely used communication model $(\mathrm{n}=11)$. All studies had a positive impact on clinical outcomes and three studies did not provide significant result on therapy adherence. The use of telepharmacy can be maximized and used on a vast scale, with the design of devices and technologies making it easier for pharmacists and diabetic patients to provide and receive clinical pharmaceutical services during the COVID-19 pandemic.
\end{abstract}

Keywords: pharmacist, clinical pharmaceutical services, diabetes mellitus, telepharmacy, COVID-19

\section{Introduction}

The Coronavirus Disease 2019 (COVID-19) pandemic has emerged since the end of 2019 and disrupted many human activities, especially in the healthcare sector. ${ }^{1,2}$ COVID-19 is a respiratory disease caused by infection with the SARS-CoV-2 (Severe Acute Respiratory Syndrome Coronavirus-2) virus which was first diagnosed in December 2019. The disease is believed to have first spread from Wuhan, China. The SARS-CoV-2 virus primarily affects the respiratory system, although other organs are also affected. Symptoms include fever, dry cough and fatigue and loss of sense of taste and smell. And in more serious symptoms can occur difficulty breathing, chest pain and loss of the ability to speak and move and even death. ${ }^{3,4}$ The virus is highly contagious and has a tendency to spread through droplets. This causes that the only options to prevent its spread are to impose local or national lockdowns, social-distancing, travel restrictions, and reduction of hospital/clinic schedules. $^{5-7}$ As a final measure, the COVID-19 pandemic has forced the implementation of health protocols in which people are required to keep their distance and reduce face-to-face meetings. Such regulation is also implemented in healthcare facilities so patients have to reduce routine visits. ${ }^{8,9}$
Correspondence: Nasrul Wathon Department of Pharmaceutics and Pharmaceutical Technology, Faculty of Pharmacy, Universitas Padjadjaran, Sumedang, 45363, Indonesia Email nasrul@unpad.ac.id

Keri Lestari

Department of Pharmacology and Clinical Pharmacy, Faculty of Pharmacy, Universitas Padjadjaran, Sumedang, 45363, Indonesia

Email lestarikd@unpad.ac.id 
Diabetic patients are among those most affected by the COVID-19 pandemic because they need regular clinical pharmaceutical services for monitoring patient lifestyle for disease, drug therapy management, monitoring clinical outcome parameters and drug therapy adherence. ${ }^{10}$ The use of internet of things as recommended by the International Pharmaceutical Federation (FIP) can overcome the main challenges of managing diabetes or other chronic illness patients during a pandemic, namely, the limited access to healthcare facilities, routine laboratory examinations and providing education and medicines. ${ }^{11}$

Telepharmacy is part of telemedicine and is a concept that refers to the provision of pharmaceutical services by pharmacists. The National Association of Boards of Pharmacy defines telepharmacy as pharmaceutical care delivery through the use of telecommunications and information technology for patients at distance. Telepharmacy generally involves services such as prescription drug review, drug information services, drug monitoring and patient counselling. ${ }^{11-13}$ Telepharmacy can be a potential alternative in overcoming the need for pharmaceutical services during a pandemic when the community is required to practice social distancing and reduce routine visits to healthcare facilities. ${ }^{14}$ The use of telepharmacy in providing pharmaceutical care has also been carried out in a hospital in Spain and evidence shows that telepharmacy can facilitate pharmacotherapy follow-up, patient education, clinical coordination, information-dissemination and home drug delivery. ${ }^{15}$ In 2021, electronic health information systems have developed, such as website-based applications, mobile applications and other forms, that make information more easily available to pharmacists. ${ }^{16,17}$

The presence of telepharmacy should have a positive impact on patient recovery, because telepharmacy may be useful in supporting patient that use medication when pharmacist is not physically present. ${ }^{18}$ However, currently the use of telepharmacy in diabetic patients is still poorly studied and has not been fully explored. Thus, in this review the authors discuss and evaluate the impact of pharmaceutical service interventions through telepharmacy on the care of diabetic patients and future prospects for use during the pandemic.

\section{Methods}

This review includes research articles from the PubMed journal database that were published during 2011-2021. The literature search was performed from May to June 2021 using the following keywords: "pharmacist", "telepharmacy", “telehealth", “telephone”, 'diabetes', COVID-19' and 'pandemic'. Inclusion criteria for the articles were that they had to be in English and use the experimental method. Additional criteria are that: articles will be reviewed in the form of reports or research results that explain the practice of pharmaceutical services by pharmacists through telepharmacy technology, either SMS, telephone or other information technology; the provision of interventions is carried out at the patients home, nursing home or a series of services in health service facilities; and research outputs are in the form of clinical outcomes of diabetic patients and patient adherence with drug therapy.

As described in Figure 1, the search resulted in 67 articles, of which 53 were excluded because they did not meet the inclusion and exclusion criteria. Finally, 14 articles were available for review that discussed the use of telepharmacy for diabetic patients.

\section{Results}

Of the 67 articles identified, 14 research articles met the specified inclusion and exclusion criteria. The articles obtained were published between 2011 and 2021. The research was carried out in various regions: Asia, Africa, Europe and America. All studies used the experimental method, such as randomized or non-randomized controlled trial and prospective single-cohort study.

The majority of the articles $(n=12)$ used a research method in a randomized controlled trial. There are several telepharmacy technologies used in providing interventions, including telephone $(\mathrm{n}=11)$, electronic messages $(\mathrm{n}=2)$, web-based programs $(\mathrm{n}=1)$ and special electronic devices (n $=2)$. The interventions included counselling $(\mathrm{n}=8)$, monitoring clinical parameters $(\mathrm{n}=4)$, monitoring drug use $(\mathrm{n}=$ 6), patient education $(\mathrm{n}=3)$ and virtual management by a multidisciplinary team $(n=2)$. All studies focused on the adult patient population. All of the studies gave positive results for clinical outcomes management. Overall, there were no studies that had a negative impact on both outcomes and there were three studies that did not have a significant impact on medication adherence after the intervention.

\section{Clinical Outcomes and Therapy Adherence Toward Telepharmacy: Pre- Pandemic}

Table 1 describes the activities of telepharmacy intervention in diabetic patients during pre-pandemic conditions from 2012 to 2019 with clinical outcomes results. In 


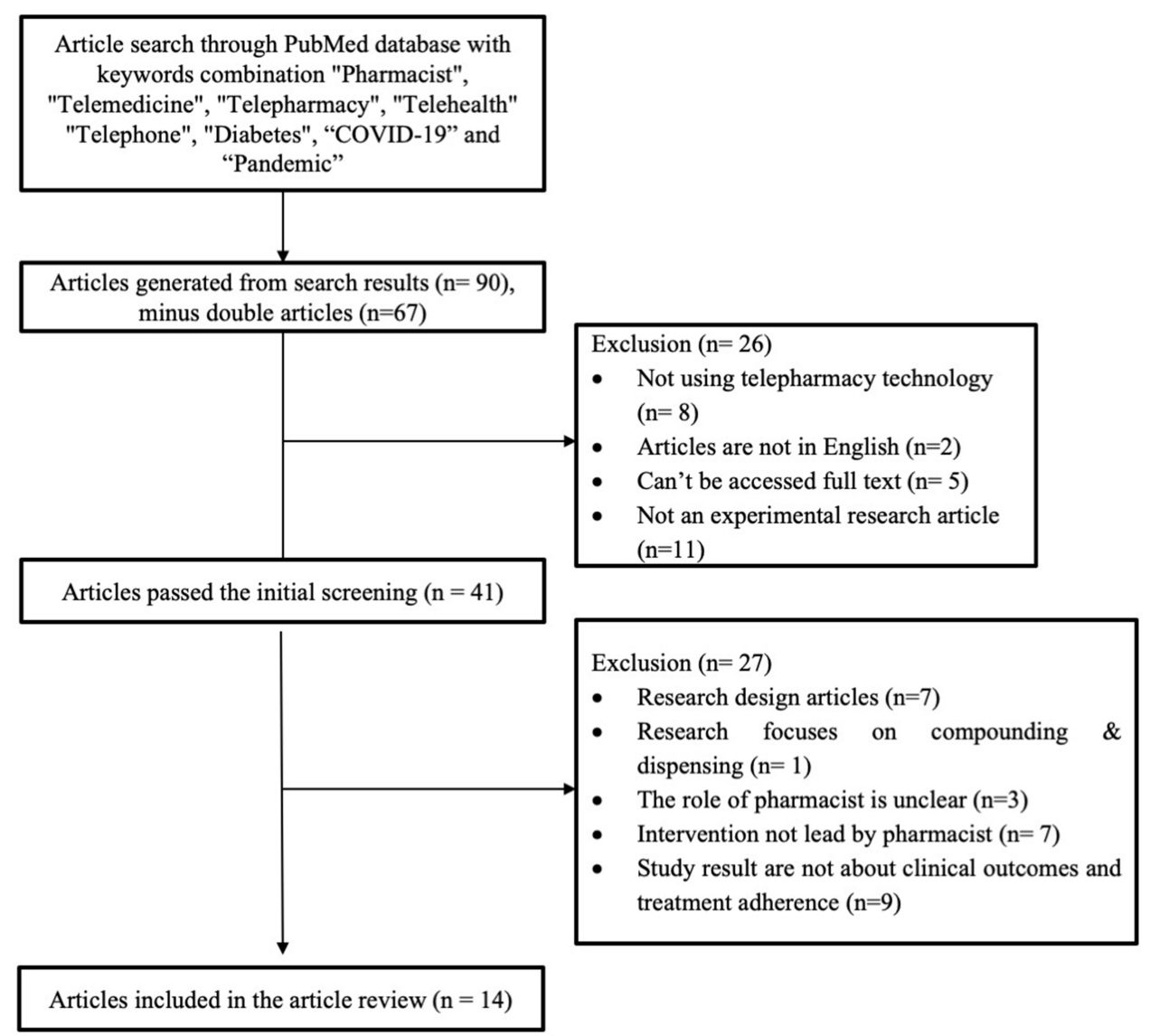

Figure I Flow chart of literature search.

addition, Table 2 describes the medication adherence results. The use of telepharmacy in diabetic patients as a whole gave positive results on clinical outcomes, as seen from the improvement in $\mathrm{HbAlc}$ values and blood sugar levels, ${ }^{16-18,25,26}$ as well as positive results on patient adherence to treatment therapy, ${ }^{23,25,27,29,30}$ although three studies gave a neutral result because the intervention did not give a significant result when compared to a control group. ${ }^{16-28}$

As previously stated, this review article classifies study outcomes into two categories based on reported outcomes: clinical outcomes and treatment adherence. Studies that reported outcomes related to patient clinical outcome parameters were primarily monitoring laboratory values $(\mathrm{n}=11)$. Studies reporting outcomes related to treatment adherence $(\mathrm{n}=8)$.

\section{Clinical Outcomes and Therapy Adherence Toward Telepharmacy: The COVID-19 Pandemic}

The COVID-19 pandemic has changed the way people interact in order to minimize exposure to infection.
Telepharmacy for diabetic patients as an alternative health care method is a new approach to provide pharmacist care remotely and without face-to-face meetings. One study conducted in Saudi Arabia describes the impact of telepharmacy use in patients with uncontrolled type 2 DM during the COVID-19 pandemic. This study was conducted using a prospective single-cohort pre-post intervention method carried out by a multidisciplinary team of physicians, clinical pharmacists, diabetes educators and other healthcare professionals. Interventions were carried out by reviewing medical records and the latest laboratory examinations by doctors; patients then received appropriate treatment counselling and therapy from clinical pharmacists and can be referred to diabetes educators when needed. The impact of the virtual clinic on clinical outcomes and medication adherences was evaluated before and after the implementation of telepharmacy. Assessment of the HbA1c level showed that HbA1c decreased significantly from $9.98 \pm 1.33$ before the intervention to $8.32 \pm$ 1.31 after the intervention (mean difference $=1.66 \pm 1.29$, $\mathrm{CI}=1.43-1.88 ; p<0.001)$. The need for in-person care 


\begin{tabular}{|c|c|c|}
\hline $\begin{array}{l}\frac{0}{2} \\
\frac{1}{2} \\
0\end{array}$ & $\begin{array}{l}0 \\
\frac{2}{\bar{z}} \\
\frac{3}{2}\end{array}$ & $\frac{0}{\frac{2}{2}}$ \\
\hline 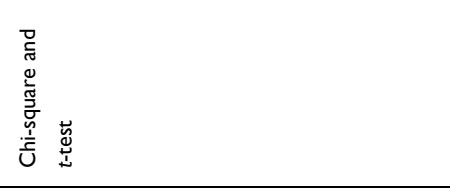 & 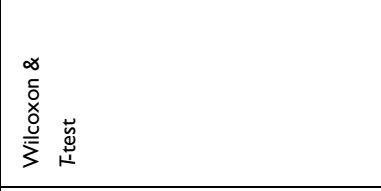 & 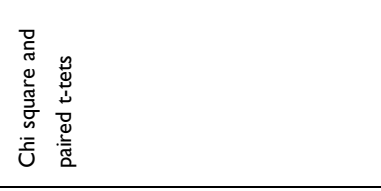 \\
\hline 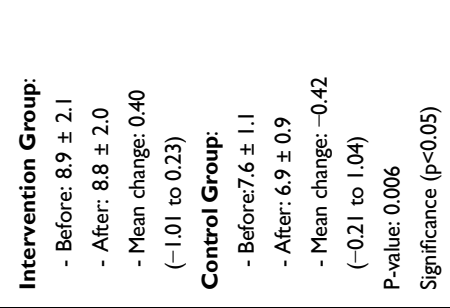 & 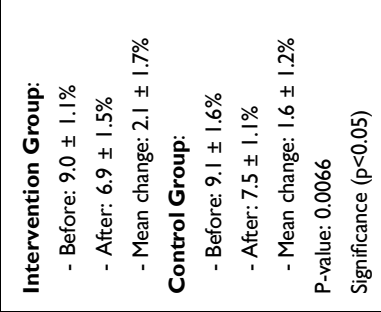 & 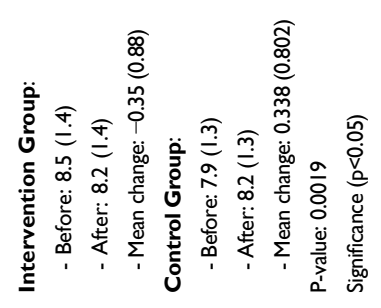 \\
\hline 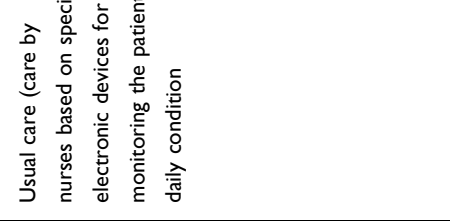 & 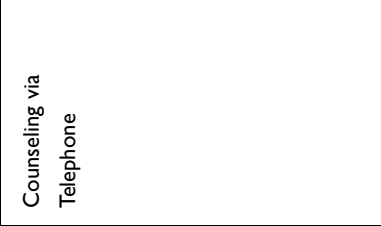 & 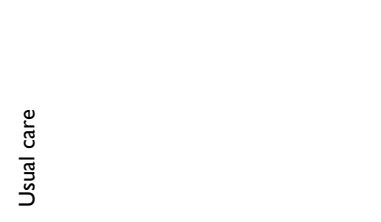 \\
\hline 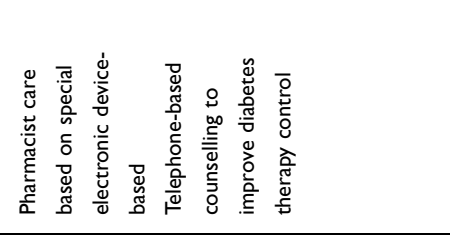 & 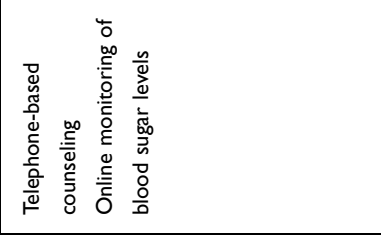 & 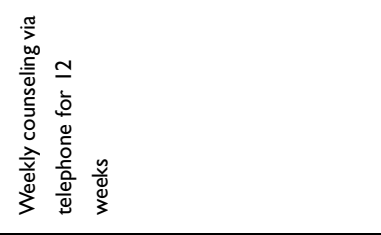 \\
\hline$\stackrel{\circ}{\circ}$ & 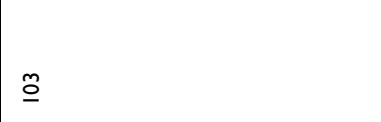 & $\stackrel{\infty}{\infty}$ \\
\hline 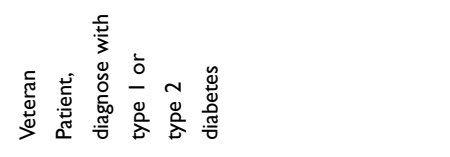 & 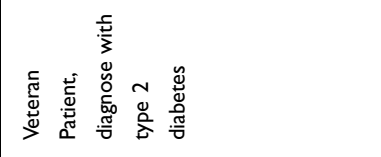 & 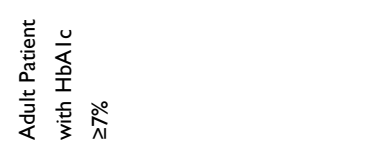 \\
\hline 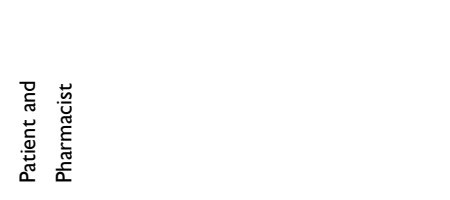 & 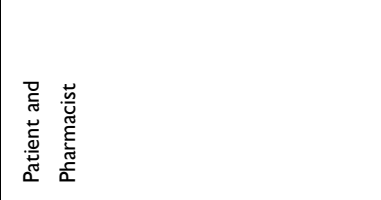 & 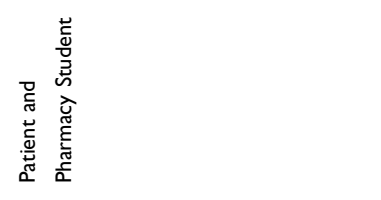 \\
\hline 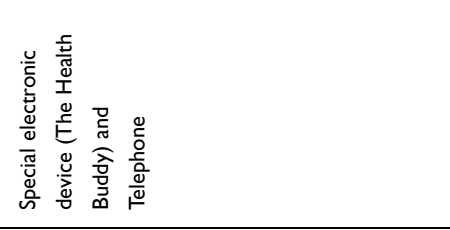 & 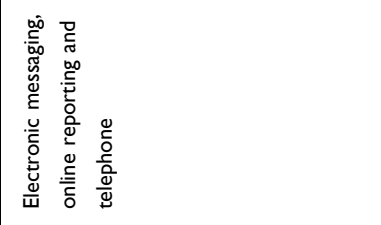 & 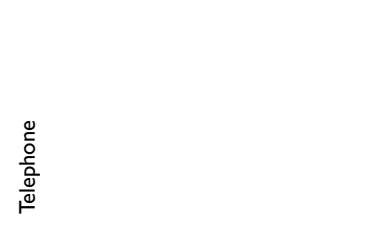 \\
\hline 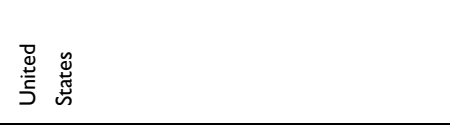 & 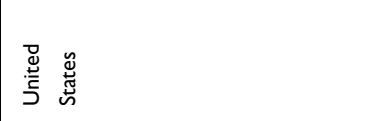 & 䲱总 \\
\hline$\stackrel{\breve{s}}{.}$ & $\begin{array}{l}\dot{⿳ 亠 亠 幺 t ~} \\
z \\
\end{array}$ & $\underset{\propto}{t}$ \\
\hline 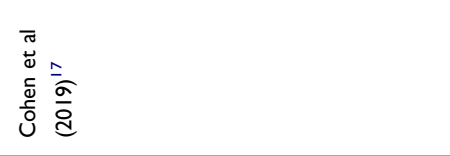 & 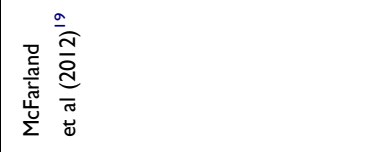 & 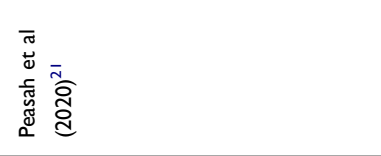 \\
\hline
\end{tabular}




\begin{tabular}{|c|c|c|c|}
\hline 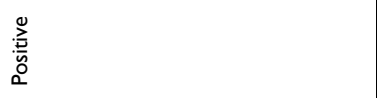 & 咅 & $\stackrel{0}{\stackrel{2}{2}}$ & 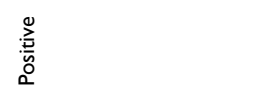 \\
\hline 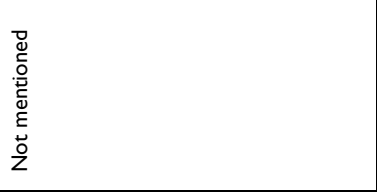 & 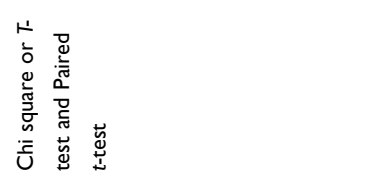 & 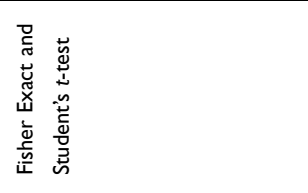 & 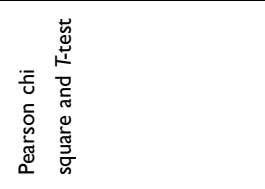 \\
\hline 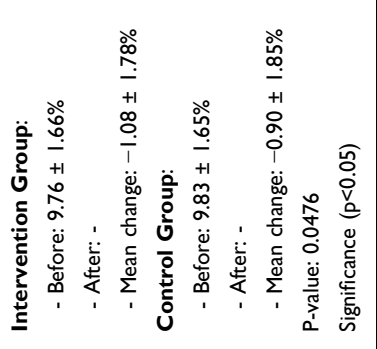 & 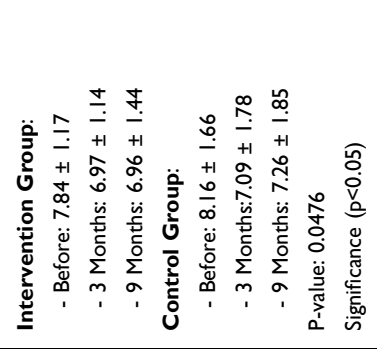 & 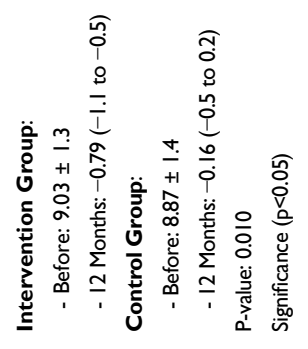 & 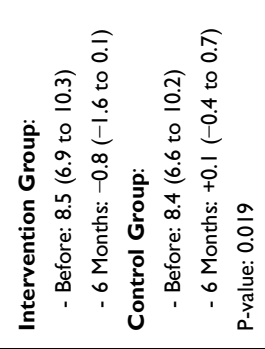 \\
\hline 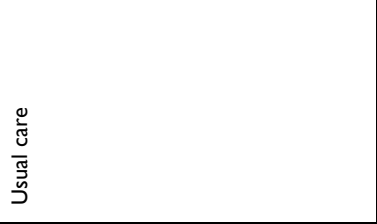 & 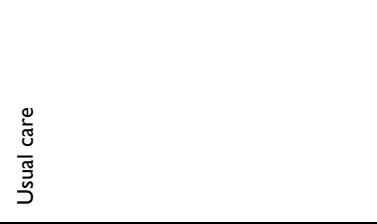 & 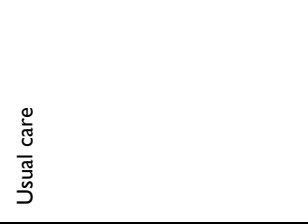 & 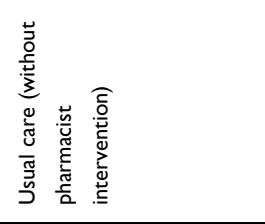 \\
\hline 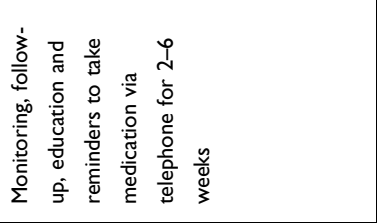 & 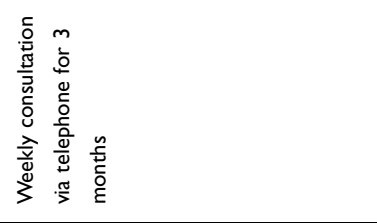 & 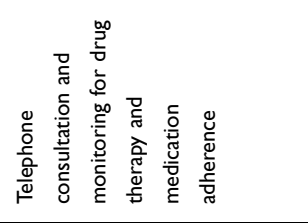 & 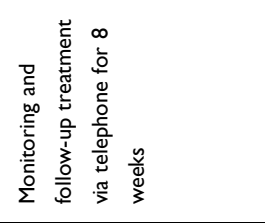 \\
\hline$\stackrel{\infty}{\underset{\sim}{\infty}}$ & $\underline{8}$ & ळ & ڤ̊ \\
\hline 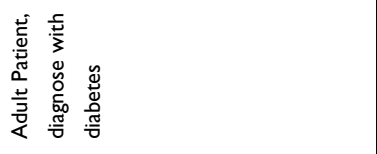 & 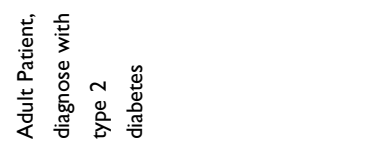 & 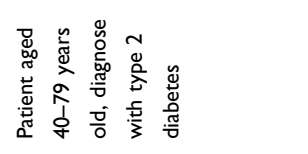 & 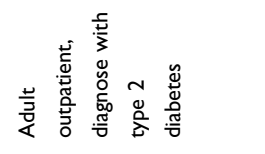 \\
\hline 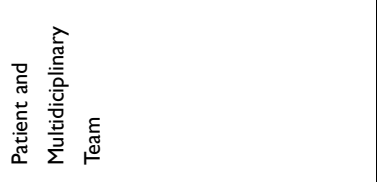 & 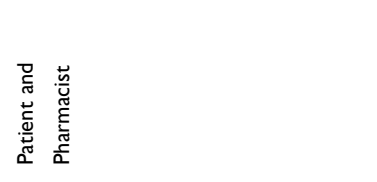 & 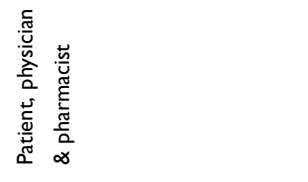 & 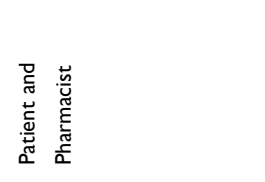 \\
\hline 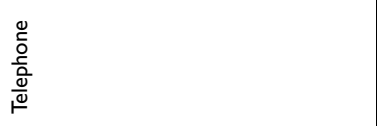 & 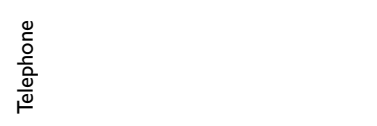 & 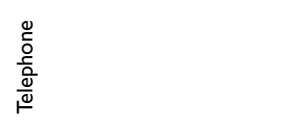 & 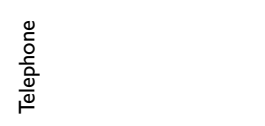 \\
\hline 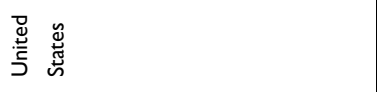 & $\underline{\underline{\underline{\underline{I}}}}$ & $\begin{array}{l}\overline{\overline{\widetilde{g}}} \\
\overline{\tilde{D}}\end{array}$ & $\begin{array}{l}\frac{5}{\frac{5}{7}} \\
\text { 흐 }\end{array}$ \\
\hline$\underset{\propto}{\mathfrak{v}}$ & $\underset{\propto}{\mathfrak{t}}$ & $\underset{\propto}{\mathfrak{t}}$ & $\underset{\propto}{\mathfrak{t}}$ \\
\hline 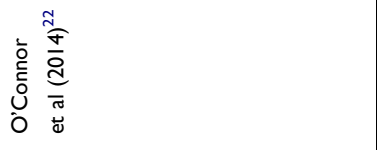 & 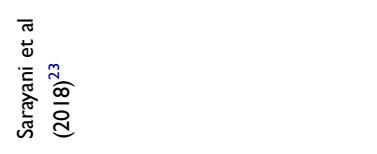 & 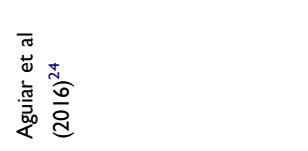 & 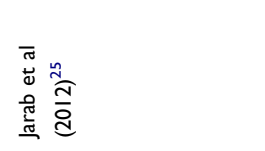 \\
\hline
\end{tabular}




\begin{tabular}{|c|c|c|c|}
\hline 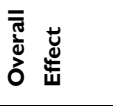 & $\begin{array}{l}\text { 辛 } \\
\text { 产 } \\
0\end{array}$ & 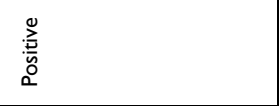 & $\begin{array}{l} \\
\text { 产 } \\
0 \\
0\end{array}$ \\
\hline & 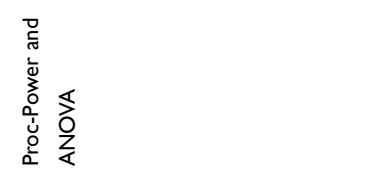 & 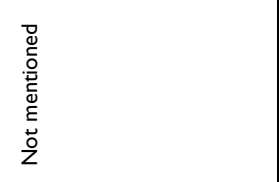 & 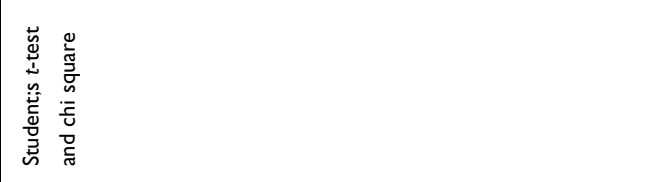 \\
\hline 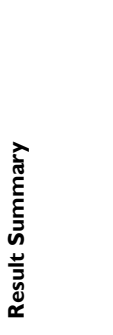 & 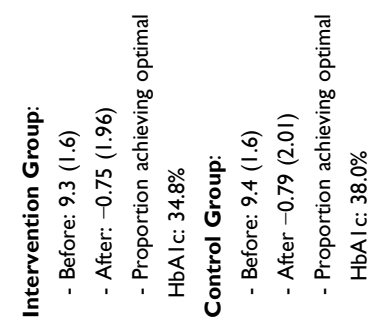 & 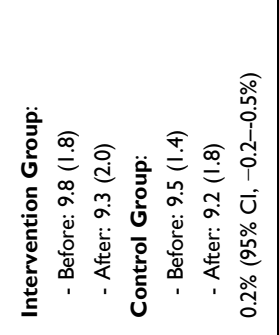 & 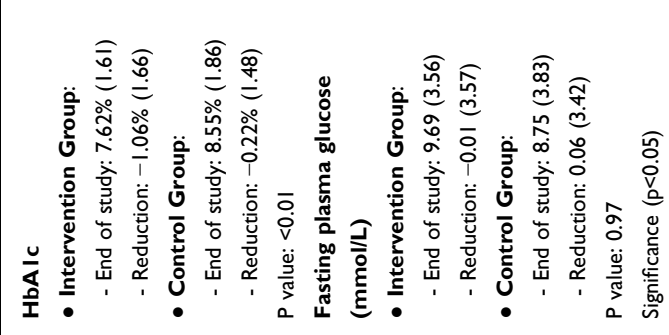 \\
\hline 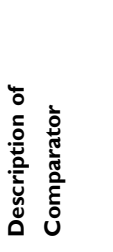 & 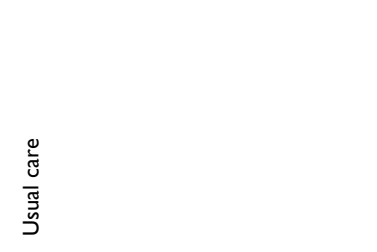 & 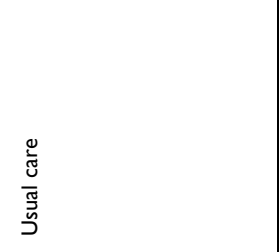 & 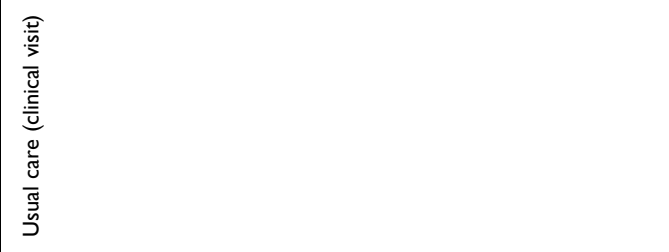 \\
\hline 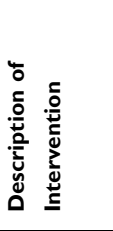 & 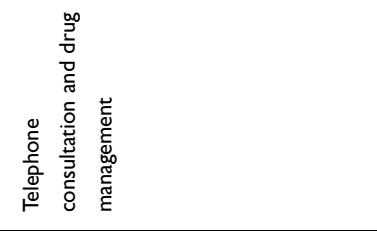 & 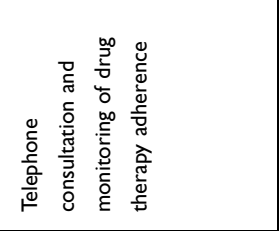 & 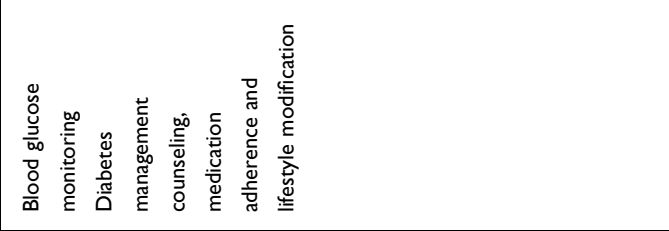 \\
\hline 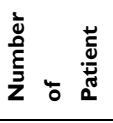 & 亲 & $\begin{array}{l}\infty \\
\stackrel{+}{a} \\
\end{array}$ & $\stackrel{\infty}{\infty}$ \\
\hline 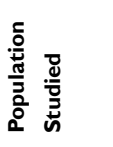 & 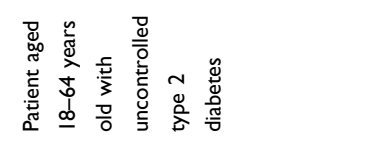 & 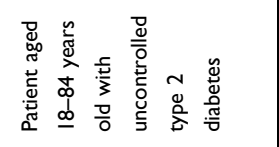 & 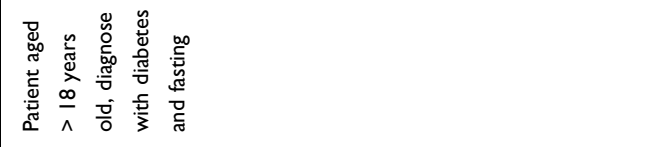 \\
\hline 密 & 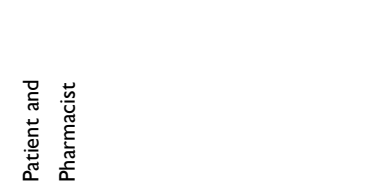 & 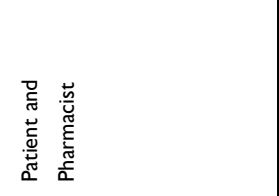 & 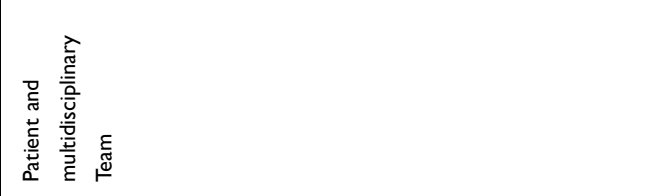 \\
\hline 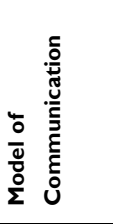 & 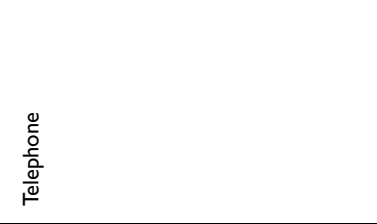 & 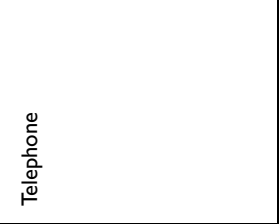 & 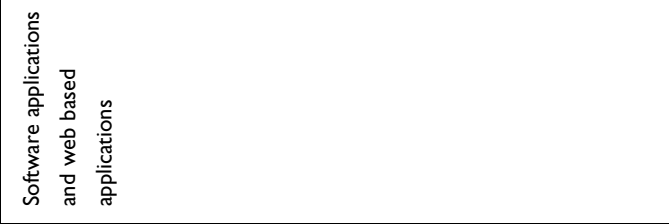 \\
\hline نे & 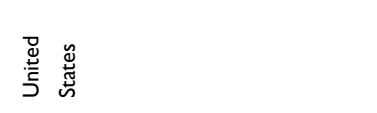 & 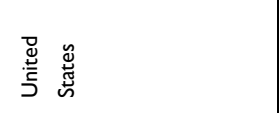 & 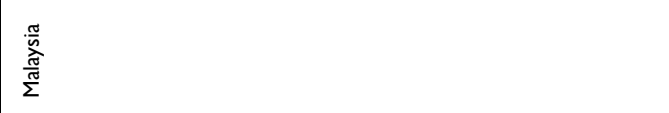 \\
\hline 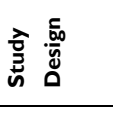 & $\begin{array}{l}5 \\
\longleftarrow \\
\end{array}$ & $\begin{array}{l}5 \\
\propto \\
\end{array}$ & 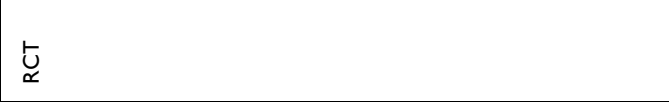 \\
\hline & 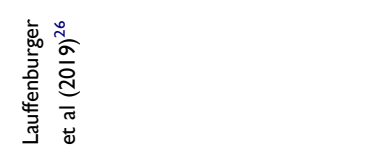 & 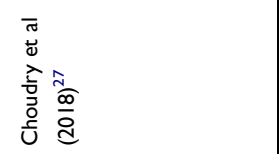 & 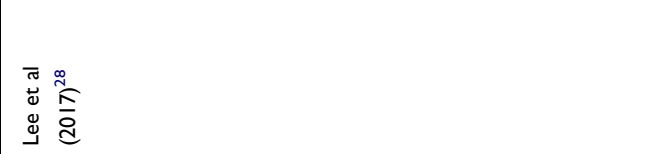 \\
\hline
\end{tabular}




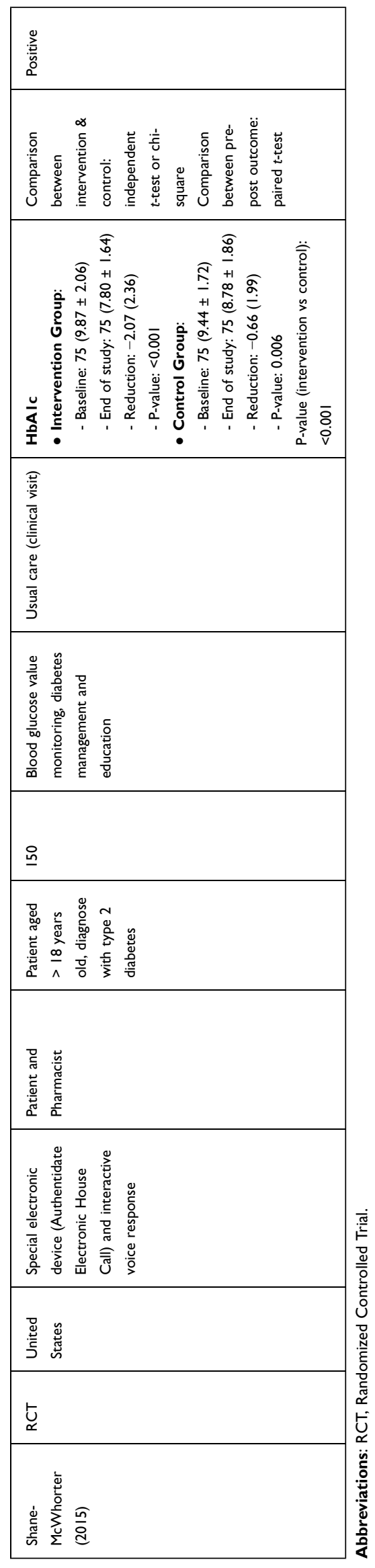

visits was also assessed during the use of telepharmacy. In pre-pandemic conditions, high-risk diabetic patients required visits every 1-2 weeks; however, with the use of virtual clinics the frequency of in-person visits has greatly decreased. For the majority of patients (64\%), only one or two visits were required during the 4-month study period. ${ }^{32}$

\section{Discussion and Future Perspectives}

Telepharmacy as an alternative healthcare method is becoming a new approach to providing pharmacist care, such as support with drug management for chronic conditions. The use of communication and information technology in pharmaceutical practice is not a new concept; in fact, based on published evidence, this practice has been carried out for 20 years. ${ }^{33}$ However, until now there have not been many articles discussing and summarizing the evidence of the impact of providing pharmaceutical services via this technology. ${ }^{31,34}$ Thus, in this review article the authors discuss the impact of interventions on clinical outcome management outputs and patient adherence to therapy.

Telepharmacy is effective in providing care for DM patients, especially during the COVID-19 pandemic when direct care is not possible. However, based on the results of the study, ${ }^{32}$ several factors must be considered for the success of pharmaceutical services. First, there must be good regulation and coordination between all health workers and the parties involved. Second, it is important to categorize patients according to their condition status. This is because the condition of some high-risk patients may worsen and require immediate intervention, as further delay may lead to further complications. In addition, some patients, such as new DM patients or patients who are prescribed a new drug that requires special training (e.g insulin injections), need to be trained to ensure safe and proper use.

There are many forms of telepharmacy used in the research articles reviewed, such as providing interventions with online-based applications, special devices or telephones. The studies included in this review varied in the frequency and intensity of telepharmacy interventions. The most commonly used method of delivering interventions is through telephone communication without using video. This is because the telephone is still considered an effective communication model and is commonly used so that it can be accessed by almost everyone. In addition, telephone is also a form of synchronous or real-time telepharmacy 


\begin{tabular}{|c|c|c|}
\hline 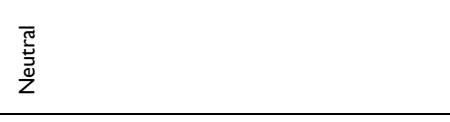 & 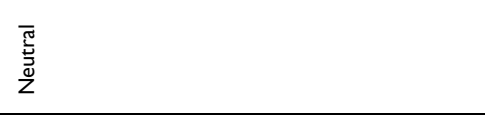 & $\begin{array}{l} \\
\\
\\
\end{array}$ \\
\hline 总 & 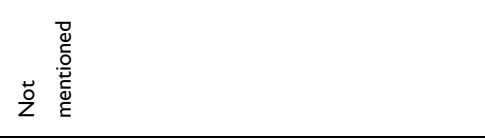 & 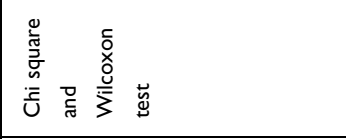 \\
\hline 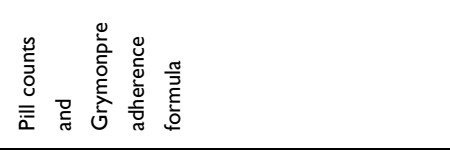 & 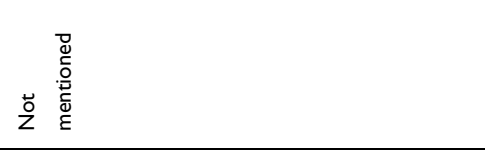 & 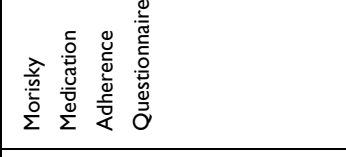 \\
\hline 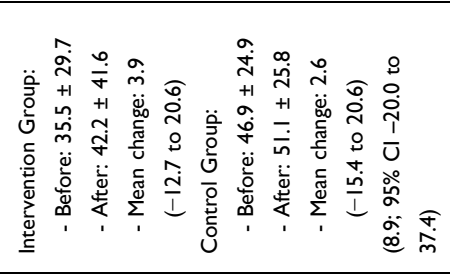 & 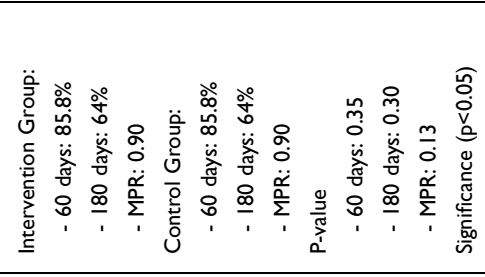 & 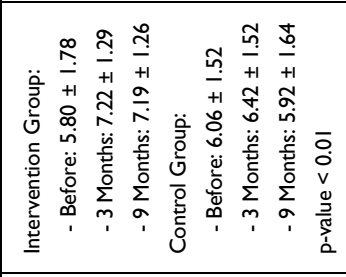 \\
\hline 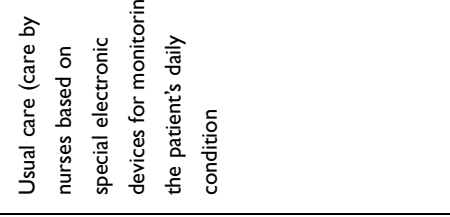 & 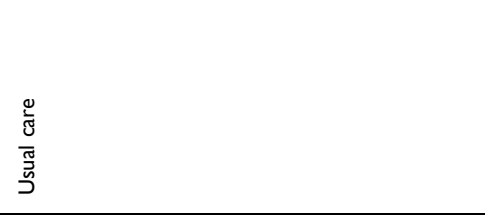 & 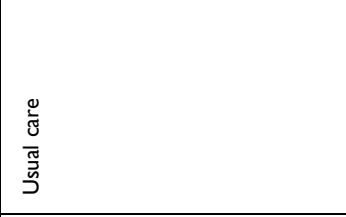 \\
\hline 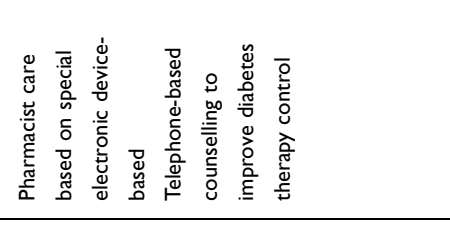 & 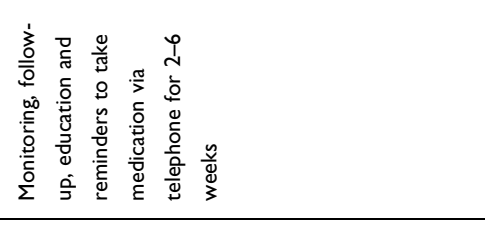 & 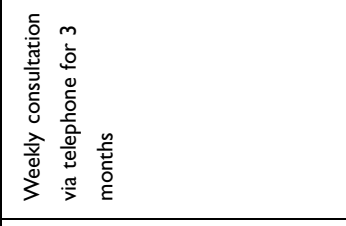 \\
\hline$\stackrel{m}{\circ}$ & 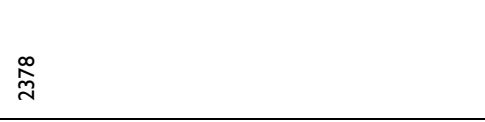 & $\underline{8}$ \\
\hline 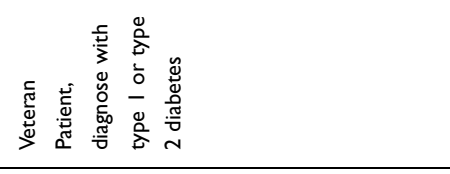 & 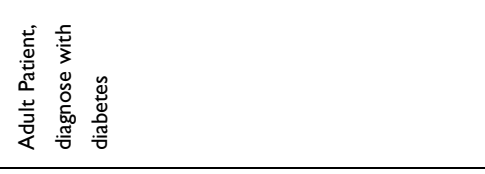 & 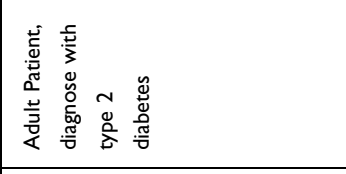 \\
\hline 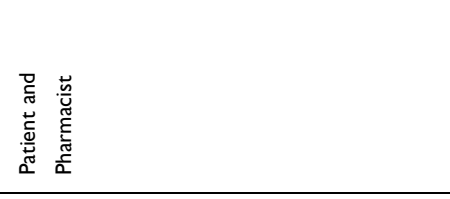 & 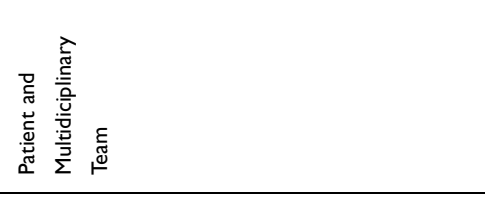 & 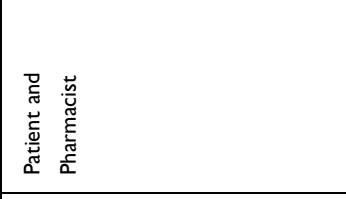 \\
\hline 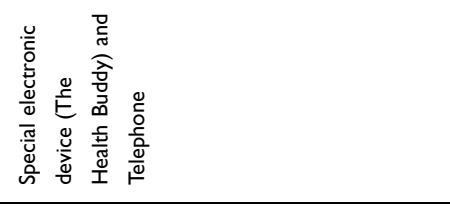 & 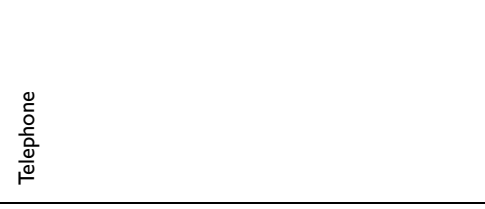 & 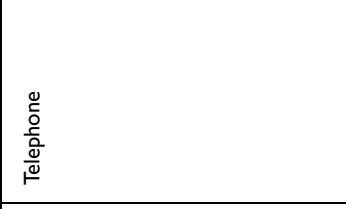 \\
\hline $\begin{array}{l}\text { 总总 } \\
\end{array}$ & 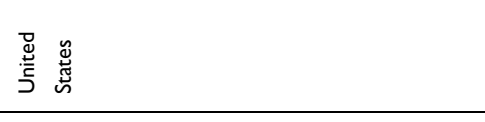 & $\underline{\underline{\underline{\underline{\underline{\underline{I}}}}}}$ \\
\hline$\underset{\Sigma}{5}$ & $\bar{\Psi}$ & $\begin{array}{l}\bar{u} \\
\end{array}$ \\
\hline 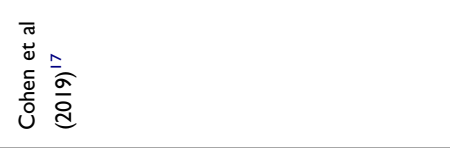 & 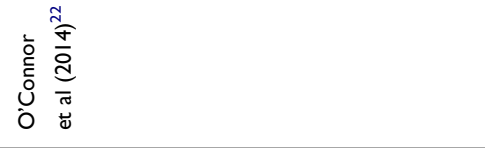 & 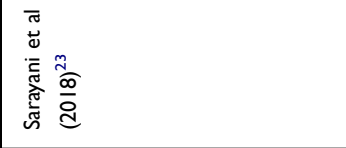 \\
\hline
\end{tabular}




\begin{tabular}{|c|c|c|c|}
\hline 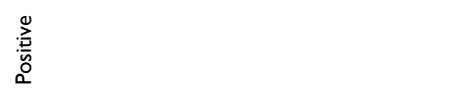 & 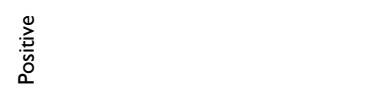 & $\begin{array}{l}\overline{\bar{v}} \\
\frac{\vec{s}}{\tilde{z}}\end{array}$ & 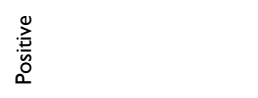 \\
\hline 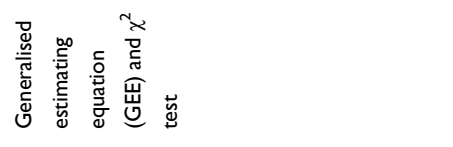 & 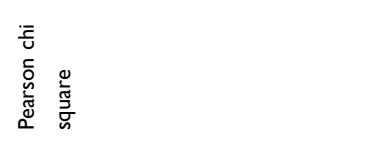 & 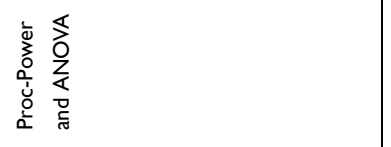 & 雚 \\
\hline 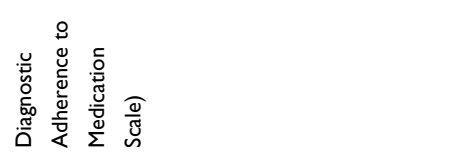 & 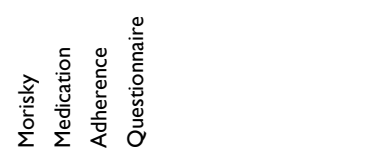 & 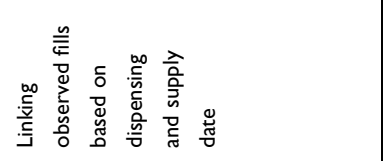 & 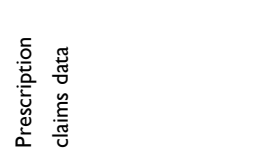 \\
\hline 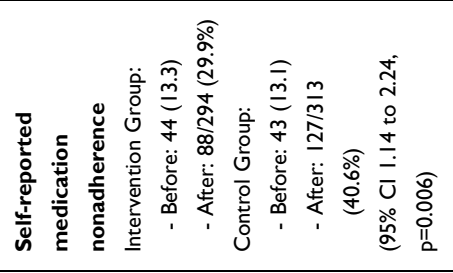 & 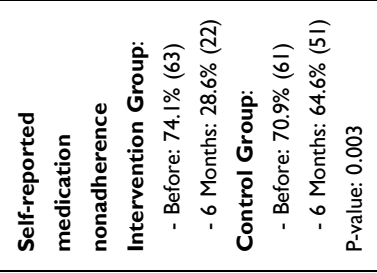 & 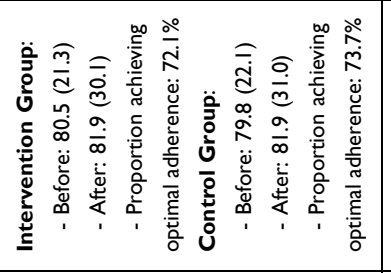 & 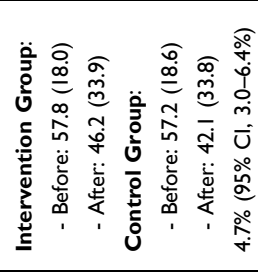 \\
\hline 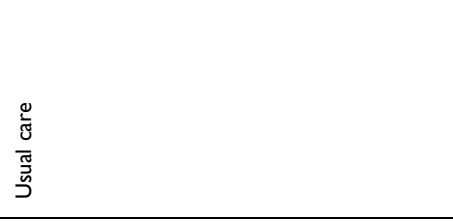 & 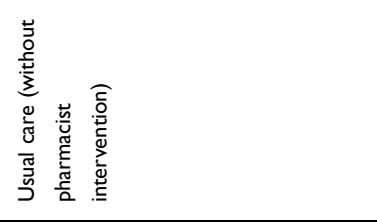 & 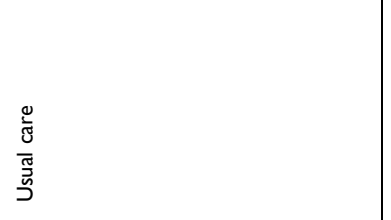 & 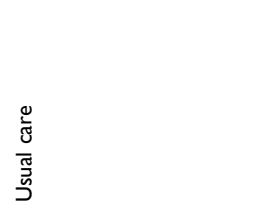 \\
\hline 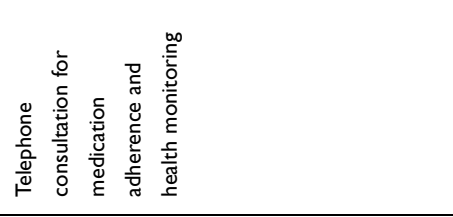 & 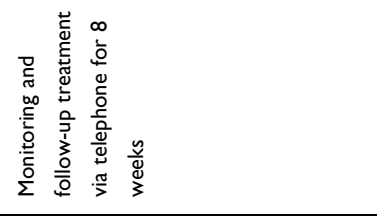 & 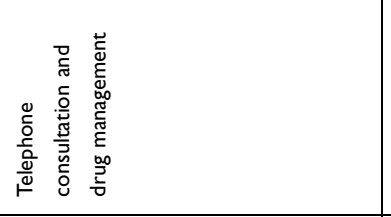 & 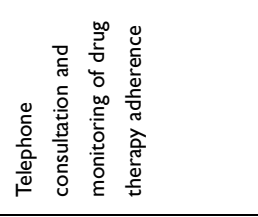 \\
\hline 志 & $\stackrel{\stackrel{n}{n}}{ }$ & 守 & $\stackrel{\infty}{\stackrel{\infty}{a}}$ \\
\hline 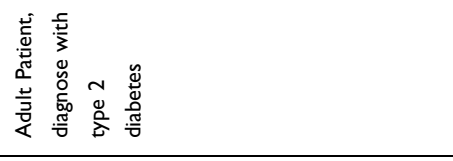 & 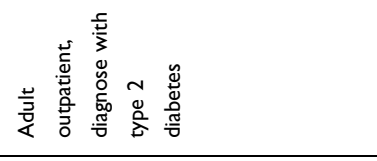 & 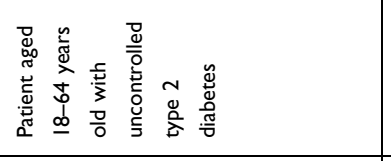 & 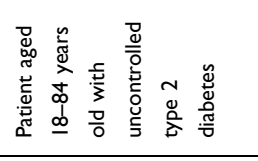 \\
\hline 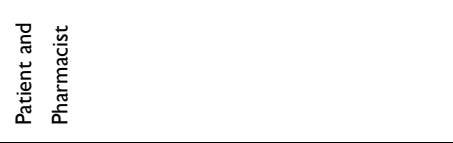 & 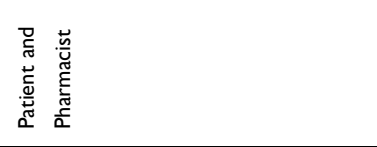 & 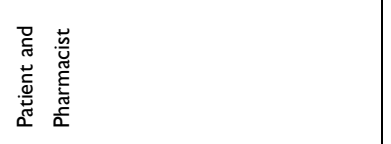 & 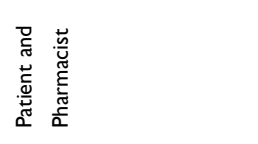 \\
\hline & 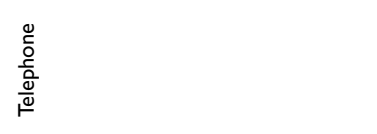 & 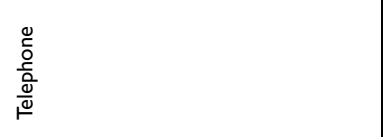 & $\begin{array}{l}\frac{0}{0} \\
\frac{0}{0} \\
\frac{0}{0} \\
\frac{0}{\sigma}\end{array}$ \\
\hline 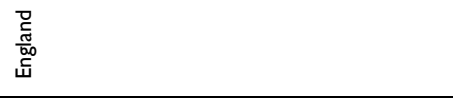 & $\begin{array}{l}\text { 胥 } \\
\text { 音 } \\
\end{array}$ & 韋 & 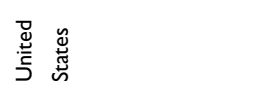 \\
\hline$\underset{\nwarrow}{\mathfrak{z}}$ & $\underset{\propto}{\mathfrak{u}}$ & $\underset{\propto}{\mathfrak{s}}$ & $\underset{\propto}{\mathfrak{t}}$ \\
\hline 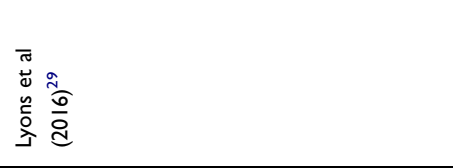 & 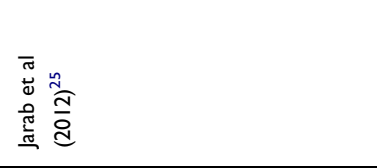 & 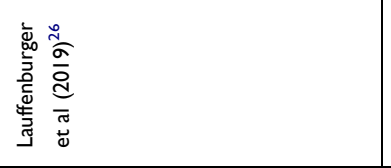 & 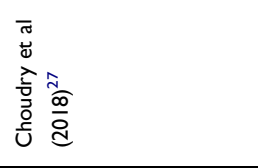 \\
\hline
\end{tabular}




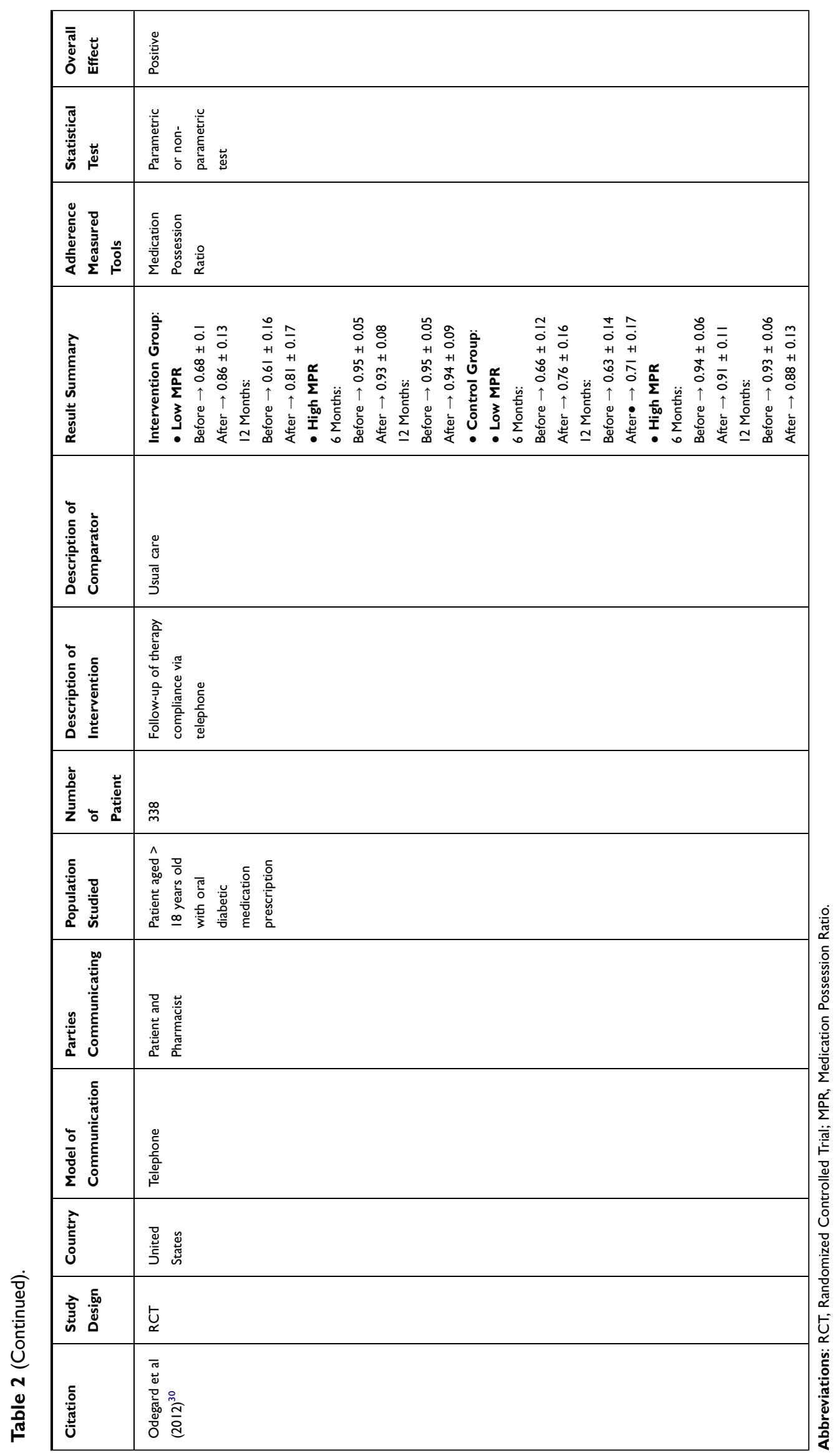


that requires the presence of the patient and pharmacist at the same time $\mathrm{e}^{35}$ so that interaction and communication can be carried out directly and the delivery of information becomes more effective.

The studies included in this literature review vary in describing the care provided to the control group. The majority of studies did not describe the usual care provided and the involvement of pharmacists in the usual care of the control group. ${ }^{21-24,26,27,29,30}$ However, several studies describe the usual care received, such as care by nurses, and patients receive equivalent onsite education and care but do not receive follow-up or monitoring via telepharmacy. ${ }^{17,19,20,25,28}$

In general, most of the interventions, both in conditions before the pandemic and during the pandemic, had a positive impact and there were only three studies that did not provide significant results: in these three studies, conducted by Cohen et $\mathrm{al}^{17}$ O'Connor et $\mathrm{al}^{22}$ and Lauffenburger et $\mathrm{al}^{26}{ }^{26}$ telepharmacy intervention was carried out to improve patient adherence to medication therapy. The results of the study by O'Connor et $\mathrm{al}^{22}$ were not significant because it was given at a low intensity where the patient received a call for 5 minutes within 2-3 weeks of the intervention. On the other hand, the similar intervention in another case that included more contact times with the patient gave good results. ${ }^{36,37}$ The results of the study by Cohen et al ${ }^{17}$ did not have a significant difference between the intervention group and the control group in terms of adherence, this may have been due to more experience in the use of telepharmacy in the control group (telehealth led-nurse) compared to the intervention group administered by pharmacists. While the research conducted by Lauffenburger et $\mathrm{al}^{26}$ did not show significant results on therapy adherence because there were only $30 \%$ of patients who received initial pharmacist consultation interventions, so even though the contact rate was achieved, the value was low and affected the results of the research conducted.

Research on the use of telepharmacy for diabetic patients during the COVID-19 pandemic is still very limited. The only study results the authors obtained were Tourkmani et al. ${ }^{32}$ The study showed positive results with the provision of interventions by a multidisciplinary team led by pharmacists. Another study on the use of telepharmacy during the COVID-19 pandemic in outpatients is conducted by Poderoso et $\mathrm{al}^{38}$ showed that the patients get clinical follow-up and therapeutic adherence monitoring with free home delivery of medication reducing outpatient visits by $56 \%$, the average patient visit before the pandemic was $215 \pm 25$ and the average visit during a pandemic after telepharmacy implemented was $95 \pm 29$. Also, study conducted by Calil-elias et al ${ }^{39}$ using telepharmacy to improve patient compliance in the use of oral antineoplastic agents stated that 53 patients had a Medication Possession Ratio (MPR) between 90-110\% and 52 patients had a Proportion of Days Covered (PDC) value greater than or equal to $90 \%$. These studies proved that the use of telepharmacy during the COVID-19 pandemic, especially for diabetic patients, has a good impact and able to improve clinical outcomes and patient therapy adherence, and can reduce patient visits to hospitals or health care facilities, which is an important factor in the pandemic.

Although research into the impact of telepharmacy on diabetes was mostly documented before the development of the COVID-19 pandemic, the results of these studies use fundamental principles and implementation examples that can illustrate the use of telepharmacy during the COVID-19 pandemic. $^{34}$

And although this literature review compiles a wide variety of clinical pharmaceutical services delivered to diabetic patients via telepharmacy, it is likely that many are not covered (examples: those that are currently used but have not yet been published). It is also possible that this review article does not cover all the examples of pharmacist involvement because it depends on how the pharmacist's role is referred to in the article. In addition, because this review article focused on clinical outcomes and patient adherence to therapy, studies on cost-effectiveness and productivity were not assessed.

\section{Conclusion}

The use of telepharmacy for the treatment of diabetic patients has been shown to be successful in positively improving clinical outcomes and patient adherence to therapy. The use of telepharmacy has also succeeded in overcoming restrictions on routine visits for diabetic patients to healthcare facilities. The COVID-19 pandemic has demonstrated that telepharmacy can be beneficial when used in diabetic patients and would be particularly beneficial if it was formally integrated into diabetes care to replace in-person care visits, despite data limitations. However, implementing and continuing the use of telepharmacy in non-pandemic times has shown success in providing access to care for diabetic patients. Future studies should increase the use of telepharmacy during a 
pandemic for patients with diabetes and other chronic diseases and focus on ways to improve the telepharmacy experience for patients.

\section{Acknowledgments}

We thank Institut Pembangunan Jawa Barat Universitas Padjadjaran (Injabar Unpad) for supporting this research.

\section{Disclosure}

The authors report no conflicts of interest in this work.

\section{References}

1. Zhang JJ, Dong X, Cao YY, et al. Clinical characteristics of 140 patients infected with SARS-CoV-2 in Wuhan, China. Allergy Eur J Allergy Clin Immunol. 2020;75:7. doi:10.1111/all.14238

2. Di Gennaro F, Pizzol D, Marotta C, et al. Coronavirus diseases (COVID-19) current status and future perspectives: a narrative review. Int J Environ Res Public Health. 2020;17:8. doi:10.3390/ ijerph 17082690

3. Khurshid Z, Asiri FYI, Al Wadaani H. Human saliva: non-invasive fluid for detecting novel coronavirus (2019-nCoV). Int J Environ Res Public Health. 2020;17:7. doi:10.3390/ijerph17072225

4. Peng X, Xu X, Li Y, Cheng L, Zhou X, Ren B. Transmission routes of $2019-\mathrm{nCoV}$ and controls in dental practice. Int J Oral Sci. 2020;12:1. doi:10.1038/s41368-020-0075-9

5. Nishiura H, Jung S, Linton NM, et al. The extent of transmission of novel coronavirus in Wuhan, China, 2020. J Clin Med. 2020;9:2. doi: $10.3390 / \mathrm{jcm} 9020330$

6. Khachfe HH, Chahrour M, Sammouri J, Salhab HA, Makki BE, Fares MY. An Epidemiological Study on COVID-19: a rapidly spreading disease. Cureus. 2020. doi:10.7759/cureus. 7313

7. Banerjee M, Chakraborty S, Pal R. Teleconsultation and diabetes care amid COVID-19 pandemic in India: scopes and challenges. $J$ Diabetes Sci Technol. 2020;14:4. doi:10.1177/1932296820929391

8. Bonora BM, Boscari F, Avogaro A, Bruttomesso D, Fadini GP. Glycaemic control among people with type 1 diabetes during lockdown for the SARS-CoV-2 outbreak in Italy. Diabetes Ther. 2020;11:6. doi:10.1007/s13300-020-00829-7

9. Nachimuthu S, Vijayalakshmi R, Sudha M, Viswanathan V. Coping with diabetes during the COVID - 19 lockdown in India: results of an online pilot survey. Diabetes Metab Syndr Clin Res Rev. 2020;14:4. doi:10.1016/j.dsx.2020.04.053

10. Ghosh A, Gupta R, Misra A. Telemedicine for diabetes care in India during COVID19 pandemic and national lockdown period: guidelines for physicians. Diabetes Metab Syndr Clin Res Rev. 2020;14:4. doi:10.1016/j.dsx.2020.04.001

11. Casey MM, Sorensen TD, Elias W, Knudson A, Gregg W. Current practices and state regulations regarding telepharmacy in rural hospitals. Am J Heal Pharm. 2010;67:13. doi:10.2146/ajhp090531

12. Keeys C, Kalejaiye B, Skinner M, et al. Pharmacist-managed inpatient discharge medication reconciliation: a combined onsite and telepharmacy model. Am J Heal Pharm. 2014;71:24. doi:10.2146/ ajhp130650

13. Sankaranarayanan J, Murante LJ, Moffett LM, Retrospective A. Evaluation of remote pharmacist interventions in a telepharmacy service model using a conceptual framework. Telemed e-Health. 2014;20:10. doi:10.1089/tmj.2013.0362

14. Di Cerbo A, Morales-Medina JC, Palmieri B, Iannitti T. Narrative review of telemedicine consultation in medical practice. Patient Prefer Adherence. 2015;9. doi:10.2147/PPA.S61617.
15. Morillo-Verdugo R, Margusino-Framiñán L, Monte-Boquet E, et al. Spanish society of hospital pharmacy position statement on telepharmacy: recommendations for its implementation and development. Farm Hosp. 2020;44(4):174-181. doi:10.7399/fh.11515

16. Song Z, Hu Y, Zheng S, Yang L, Zhao R. Hospital pharmacists' pharmaceutical care for hospitalized patients with COVID-19: recommendations and guidance from clinical experience. Res Soc Adm Pharm. 2021;17:1. doi:10.1016/j.sapharm.2020.03.027

17. Cohen LB, Taveira TH, Wu WC, Pirraglia PA. Pharmacist-led telehealth disease management program for patients with diabetes and depression. $J$ Telemed Telecare. 2020;26(5):5. doi:10.1177/ $1357633 X 18822575$

18. Alexander E, Butler CD, Darr A, et al. ASHP statement on telepharmacy. Am J Heal Pharm. 2017;74(9):e236-e241. doi:10.2146/ ajhp170039

19. Mcfarland M, Davis K, Wallace J, et al. Use of home telehealth monitoring with active medication therapy management by clinical pharmacists in veterans with poorly controlled type 2 diabetes mellitus. Pharmacotherapy. 2012;32:5. doi:10.1002/j.1875-9114.2011.01038.x

20. Shane-McWhorter L, McAdam-Marx C, Lenert L, et al. Pharmacistprovided diabetes management and education via a telemonitoring program. J Am Pharm Assoc. 2015;55(5):516-526. doi:10.1331/ JAPhA.2015.14285

21. Peasah SK, Granitz K, Vu M, Jacob B. Effectiveness of a student pharmacist-led telephone follow-up intervention to improve hemoglobin A1C in diabetic patients. $J$ Pharm Pract. 2020;33:6. doi: $10.1177 / 0897190019857409$

22. O'Connor PJ, Schmittdiel JA, Pathak RD, et al. Randomized trial of telephone outreach to improve medication adherence and metabolic control in adults with diabetes. Diabetes Care. 2014;37:12. doi: $10.2337 / \mathrm{dc} 14-0596$

23. Sarayani A, Mashayekhi M, Nosrati M, et al. Efficacy of a telephonebased intervention among patients with type-2 diabetes; a randomized controlled trial in pharmacy practice. Int J Clin Pharm. 2018;40:2. doi:10.1007/s11096-018-0593-0

24. Aguiar PM, da Silva CHP, Chiann C, Dórea EL, Lyra DP, Storpirtis S. Pharmacist-physician collaborative care model for patients with uncontrolled type 2 diabetes in Brazil: results from a randomized controlled trial. J Eval Clin Pract. 2018;24:1. doi:10.1111/jep.12606

25. Jarab AS, Alqudah SG, Mukattash TL, Shattat G, Al-Qirim T. Randomized controlled trial of clinical pharmacy management of patients with type 2 diabetes in an outpatient diabetes clinic in jordan. J Manag Care Pharm. 2012;18:7. doi:10.18553/jmcp.2012.18.7.516

26. Lauffenburger JC, Ghazinouri R, Jan S, et al. Impact of a novel pharmacist-delivered behavioral intervention for patients with poorly-controlled diabetes: the ENhancing outcomes through Goal Assessment and Generating Engagement in Diabetes Mellitus (ENGAGE-DM) pragmatic randomized trial. PLoS One. 2019;14:4. doi:10.1371/journal.pone. 0214754

27. Choudhry NK, Isaac T, Lauffenburger JC, et al. Effect of a remotely delivered tailored multicomponent approach to enhance medication taking for patients with hyperlipidemia, hypertension, and diabetes the STIC2IT cluster randomized clinical trial. JAMA Intern Med. 2018;178:9. doi:10.1001/jamainternmed.2018.3189

28. Lee JY, Wong CP, Tan CSS, Nasir NH, Lee SWH. Telemonitoring in fasting individuals with type 2 diabetes mellitus during ramadan: a prospective, randomised controlled study. Sci Rep. 2017;7:1. doi:10.1038/s41598-017-10564-y

29. Lyons I, Barber N, Raynor DK, Wei L. The Medicines Advice Service Evaluation (MASE): a randomised controlled trial of a pharmacist-led telephone based intervention designed to improve medication adherence. BMJ Qual Saf. 2016;25:10. doi:10.1136/bmjqs-2015004670

30. Odegard PS, Christensen DB. MAP study: RCT of a medication adherence program for patients with type 2 diabetes. $J$ Am Pharm Assoc. 2012;52:6. doi:10.1331/JAPhA.2012.11001 
31. Olesen C, Harbig P, Buus KM, Barat I, Damsgaard EM. Impact of pharmaceutical care on adherence, hospitalisations and mortality in elderly patients. Int J Clin Pharm. 2014;36:1. doi:10.1007/s11096013-9898-1

32. Tourkmani MA, ALHarbi TJ, Rsheed AMB, et al. The impact of telemedicine on patients with uncontrolled type 2 diabetes mellitus during the COVID-19 pandemic in Saudi Arabia: findings and implications. J Telemed Telecare. 2021. doi:10.1177/1357633X20985763

33. Bynum A, Hopkins D, Thomas A, Copeland N, Irwin C. The effect of telepharmacy counseling on metered-dose inhaler technique among adolescents with asthma in rural Arkansas. Telemed $\mathrm{J}$ e-Health. 2001;7:3. doi:10.1089/153056201316970902

34. Ohl ME, Richardson K, Rodriguez-Barradas MC, et al. Impact of availability of telehealth programs on documented HIV viral suppression: a cluster-randomized program evaluation in the veterans health administration. Open Forum Infect Dis. 2019;6:6. doi:10.1093/ofid/ ofz206
35. Pallavi K, Supriya P, Sk B, Sk TF. Telepharmacy: A Benefaction for Rural Healthcare. 2019.

36. McDonald KM, Chang CSE. Through the Quality Kaleidoscope: Reflections on the Science. NCBI; 2013. Available from: http:// www.ncbi.nlm.nih.gov/pubmed/23487867. Accessed August 5, 2021.

37. Aubert RE, Herman WH, Waters J, et al. Nurse case management to improve glycemic control in diabetic patients in a health maintenance organization. A randomized, controlled trial. Ann Intern Med. 1998;129(8):605-612. doi:10.7326/0003-4819-129-8-19981015000004

38. Poderoso C, Aznarez N, Moreno P. Pharmacy service' s adaptation to the covid-19 pandemic: telepharmacy and. Eur Assoc Hosp Pharm. 2021;395. Available from: https:/www.eahp.eu/sites/default/files/ 4cps-395.pdf.

39. Calil-elias S. Use of Telepharmacy To Support Patients Using Oral Antineoplastic Agents: A Pilot Study. Research Square. 2021. doi::10.21203/rs.3.rs-472358/v1
Journal of Multidisciplinary Healthcare

\section{Publish your work in this journal}

The Journal of Multidisciplinary Healthcare is an international, peerreviewed open-access journal that aims to represent and publish research in healthcare areas delivered by practitioners of different disciplines. This includes studies and reviews conducted by multidisciplinary teams as well as research which evaluates the results or conduct of such teams or healthcare processes in general. The journal

\section{Dovepress}

covers a very wide range of areas and welcomes submissions from practitioners at all levels, from all over the world. The manuscript management system is completely online and includes a very quick and fair peer-review system. Visit http://www.dovepress.com/testimonials. php to read real quotes from published authors. 